\title{
Activation energy of the soluble-insoluble self-oscillation in an autonomous polymer chain
}

\author{
Tomoka Nakazumi ${ }^{1}$ and Yusuke Hara ${ }^{1, a *}$ \\ ${ }^{1}$ Research Institute for Sustainable Chemistry, ISC, National Institute of Advanced Industrial \\ Science and Technology, AIST, Central 5-2, 1-1-1 Higashi, Tsukuba 305-8565, Japan. \\ ay-hara@aist.go.jp
}

Keywords: Self-oscillation, $\mathrm{Ru}(\mathrm{bpy})_{3}$, BZ reaction, Polymer chain, Activation energy

\begin{abstract}
In this study, we report the activation energy of the optical self-oscillation for a polymer chain that consisted of $N$-isopropylacrylamide (NIPAAm) (25 wt $\%$ ), the Ru catalyst (5 wt $\%$ ) of the Belouzov-Zhabotinsky (BZ) reaction, and acrylamide-2-methylpropanesulfonic acid (AMPS) (75 $\mathrm{wt} \%$ ). The AMPS moiety in the polymer chain has a negative charge and works as a solubility control site in the self-oscillating polymer chain (poly(NIPAAm-co-Ru(bpy) ${ }_{3}$-co-AMPS)). The optical self-oscillation of the polymer chain at constant temperature was induced by the BZ reaction. In the $\mathrm{BZ}$ reaction, the $\mathrm{Ru}(\mathrm{bpy})_{3}$ moiety in the polymer chain undergoes redox oscillation, and at the same time, the solubility of $\mathrm{Ru}(\mathrm{bpy})_{3}$ changes periodically. Due to the cyclic redox change in the $\mathrm{Ru}(\mathrm{bpy})_{3}$ moiety, the polymer chain underwent soluble-insoluble self-oscillation. The period of the self-oscillation for the poly(NIPAAm-co-Ru(bpy) ${ }_{3}$-co-AMPS) decreased with increasing temperature, in accordance with the Arrhenius equation.
\end{abstract}

\section{Introduction}

The Belouzov-Zhabotinsky (BZ) reaction is a well-known self-oscillating redox reaction and the overall process of the BZ reaction is the oxidation of malonic acid (MA) by sodium bromate $\left(\mathrm{NaBrO}_{3}\right)$ in the presence of $\mathrm{Ru}(\mathrm{bpy})_{3}$ under strong acidic conditions [1-9]. In the $\mathrm{BZ}$ reaction, the redox oscillation of the $\mathrm{Ru}(\mathrm{bpy})_{3}$ and the solubility of the $\mathrm{Ru}(\mathrm{bpy})_{3}$ changes periodically at the same time. To cause the soluble-insoluble self-oscillation of the polymer chain, we synthesized a polymer chain with the $\mathrm{Ru}(\mathrm{bpy})_{3}$ moiety as the catalyst for the $\mathrm{BZ}$ reaction. In the $\mathrm{BZ}$ reaction, the solubility of the $\mathrm{Ru}(\mathrm{bpy})_{3}$ moiety in the polymer chain changes periodically because the solubilities of the reduced and oxidized $\mathrm{Ru}(\mathrm{bpy})_{3}$ are quite different: oxidized $\mathrm{Ru}(\mathrm{bpy})_{3}$ is hydrophilic and the reduced species is hydrophobic [10-15]. In previous studies, Hara et al. clarified the activation energy of a self-oscillating polymer chain with $10 \mathrm{wt} \%$ acrylamide-2-methylpropanesulfonic acid (AMPS). To demonstrate the effect of the $\mathrm{Ru}(\mathrm{bpy})_{3}$ content in the self-oscillating polymer chain on the activation energy, a polymer chain with $5 \mathrm{wt} \% \mathrm{Ru}(\mathrm{bpy})_{3}$ content was synthesized in this study. This is because the influence of the $\mathrm{Ru}(\mathrm{bpy})_{3}$ content on the activation energy is important for the molecular design of the self-oscillating polymer system. In addition, in this study, we evaluated the amplitude of the optical self-oscillation for the AMPS-containing polymer chain with $5 \mathrm{wt} \% \mathrm{Ru}(\mathrm{bpy})_{3}$ at different temperatures.

\section{Experimental Section}

Synthesis of Poly (NIPAAm-co-Ru(bpy) $)_{3}$-co-AMPS). Poly(NIPAAm-co-Ru(bpy) ${ }_{3}$-co-AMPS) (Fig. 1) was synthesized by radical polymerization with a total monomer concentration of $20 \mathrm{wt} \%$ utilizing 2,2'-azobisisobutyronitrile (AIBN) as the initiator in a mixture of ethanol and water $(1: 1$ $w t / w t)$. The feed composition of the monomers was NIPAAm:Ru(bpy) $)_{3}: A M P S=25: 5: 75$ (wt $\%$ ). The synthesized mixture was dialyzed by water and then by ethanol. After the dialysis process, the polymer solution was frizzed-dried. 


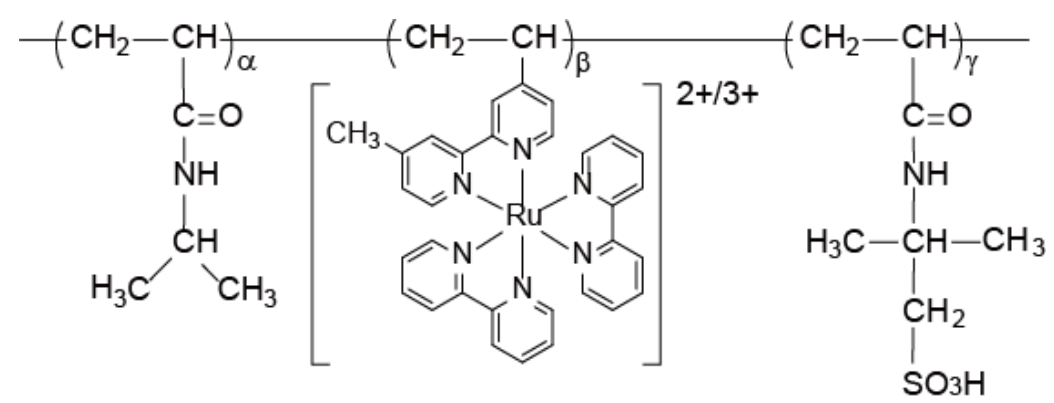

Fig. 1 Chemical structure of poly(NIPAAm-co-Ru(bpy) ${ }_{3}$-co-AMPS).

Measurement of Soluble-Insoluble Self-oscillations. To measure the soluble-insoluble self-oscillation, we prepared $0.5 \mathrm{wt} \%$ poly(NIPAAm-co-Ru(bpy) $)_{3}-\mathrm{co}$-AMPS) solutions containing fixed concentrations of the three BZ substrates: malonic acid (MA; $0.1 \mathrm{M}$ ), sodium bromate $\left(\mathrm{NaBrO}_{3} ; 0.5 \mathrm{M}\right)$, and sulfuric acid $\left(\mathrm{H}_{2} \mathrm{SO}_{4} ; 0.3 \mathrm{M}\right)$. The soluble-insoluble self-oscillating behaviors of the polymer solution were measured at several temperatures $\left(12,15,18,21,24,27\right.$, and $\left.30{ }^{\circ} \mathrm{C}\right)$ while being stirred. The $570 \mathrm{~nm}$ wavelength was used at all temperatures because this wavelength is the isosbetic point of the reduced and oxidized $\mathrm{Ru}(\mathrm{bpy})_{3}$ moieties in the polymer chain [11-13]. In all measurements, the time course of the transmittance was monitored using a UV spectrophotometer.

\section{Results and Discussion}

Fig. 2 shows the soluble-insoluble self-oscillating behavior of the poly(NIPAAm-co-Ru(bpy) $)_{3}$-co-AMPS) (see Fig. 1) solutions at 12 and $15{ }^{\circ} \mathrm{C}$. The self-oscillating behavior is attributed to the different solubilities of $\mathrm{Ru}(\mathrm{bpy})_{3}$ in the reduced and oxidized states [16]; the reduced $\mathrm{Ru}(\mathrm{bpy})_{3}$ moiety in the polymer chain is hydrophobic, while oxidized $\mathrm{Ru}(\mathrm{bpy})_{3}$ is hydrophilic. Therefore, the polymer chain with $\mathrm{Ru}(\mathrm{bpy})_{3}$ undergoes soluble-insoluble self-oscillation induced by the BZ reaction. As shown in Figs. 2 and 3, the amplitudes of self-oscillation for the poly(NIPAAm-co-Ru(bpy) ${ }_{3}$-co-AMPS) at 12 and $15{ }^{\circ} \mathrm{C}$ increased with time. In a previous study, the amplitude of the AMPS-containing polymer chain was observed to decrease with time; therefore, the transmittance self-oscillation caused damping [16]. The decrease in amplitude with time is attributed to the low solubility of the reduced $\mathrm{Ru}(\mathrm{bpy})_{3}$ moiety in the polymer chain. In the reduced state, the polymer chains aggregated owing to the hydrophobic interaction originating in the hydrophobic reduced $\mathrm{Ru}(\mathrm{bpy})_{3}$ moiety. When the soluble-insoluble self-oscillation was repeated, the size of polymer aggregation increased and the amplitude of the self-oscillation decreased with time.

In the previous study [16], the polymer chain had $10 \mathrm{wt} \% \mathrm{Ru}(\mathrm{bpy})_{3}$ content, which was twice that in this study. Moreover, the AMPS content (which had hydrophilic nature) was $40 \mathrm{wt} \%$; in this study, the polymer chain had $75 \mathrm{wt} \%$ AMPS content. Due to the lower content of the reduced $\mathrm{Ru}$ (bpy) $)_{3}$ moiety and higher content of the AMPS domain, the hydrophilicity of the polymer chain is higher in this study. Therefore, we consider that the polymer chain does not undergo damping in the transmittance self-oscillation. The increasing amplitude of the AMPS-containing polymer solution in Fig. 2 is attributed to the disaggregation of the polymer chain in the self-oscillating behavior originating from the hydrophilicity of the polymer chain [16]. As shown in Fig. 2(B), the waveform of the self-oscillation was disturbed after $\sim 1300 \mathrm{~s}$. The disturbed waveform of the transmittance self-oscillation of the polymer solution was due to $\mathrm{CO}_{2}$ bubbles generated by the $\mathrm{BZ}$ reaction. The amount of $\mathrm{CO}_{2}$ bubbles was larger at $15{ }^{\circ} \mathrm{C}$ than at $12{ }^{\circ} \mathrm{C}$ because the rate of the $\mathrm{BZ}$ reaction depends on temperature (see Fig. 4). The $\mathrm{CO}_{2}$ bubbles inhibit the long-term measurement of the self-oscillation. 

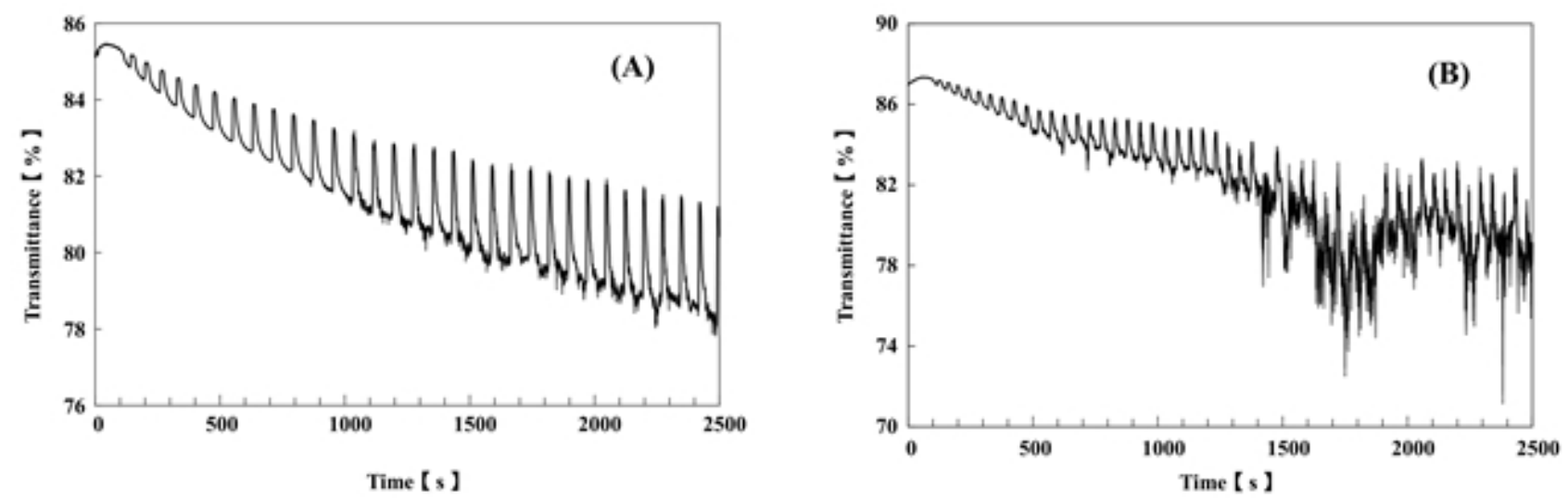

Fig. 2 Optical self-oscillations for $0.5 \mathrm{wt} \%$ poly(NIPAAm-co-Ru(bpy) $)_{3}$-co-AMPS) solutions at constant sulfuric acid, sodium bromate, and malonic acid $\left(\left[\mathrm{H}_{2} \mathrm{SO}_{4}\right]=0.3 \mathrm{M},\left[\mathrm{NaBrO}_{3}\right]=0.5 \mathrm{M}\right.$, and $[\mathrm{MA}]=0.1 \mathrm{M}):(\mathrm{A}) 12^{\circ} \mathrm{C}$, (B) $15^{\circ} \mathrm{C}$.
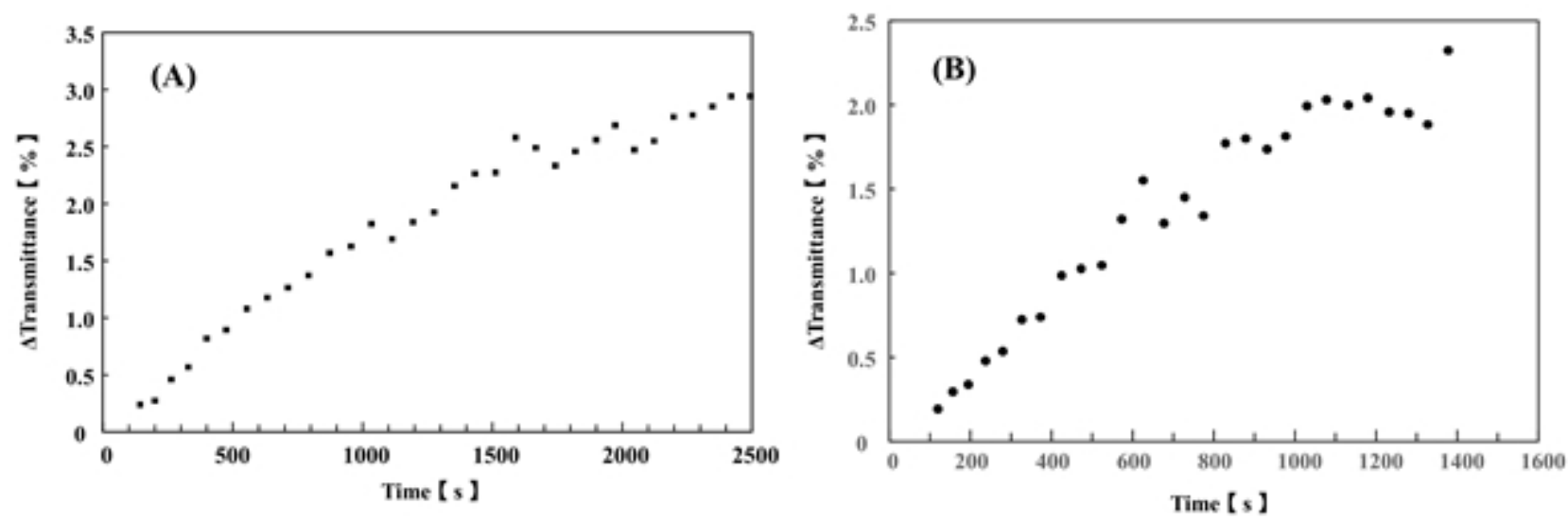

Fig. 3 Dependence of amplitude of optical self-oscillation for poly(NIPAAm-co-Ru(bpy) $)_{3}-\mathrm{co}$-AMPS) solution at $12{ }^{\circ} \mathrm{C}(\mathrm{A})$ and $15^{\circ} \mathrm{C}(\mathrm{B})$ at constant sulfuric acid, sodium bromate, and malonic acid $\left(\left[\mathrm{H}_{2} \mathrm{SO}_{4}\right]=0.3 \mathrm{M},\left[\mathrm{NaBrO}_{3}\right]=0.5 \mathrm{M},[\mathrm{MA}]=0.1 \mathrm{M}\right)$.

Fig. 4 shows the period of the optical self-oscillation of the AMPS-containing polymer solution with constant concentrations of the three $\mathrm{BZ}$ substrates $\left(\left[\mathrm{H}_{2} \mathrm{SO}_{4}\right]=0.3 \mathrm{M},\left[\mathrm{NaBrO}_{3}\right]=0.5 \mathrm{M},[\mathrm{MA}]\right.$ $=0.1 \mathrm{M})$ as a function of temperature $\left(12-30{ }^{\circ} \mathrm{C}\right)$. As shown in Fig. 4 , the oscillating period of the AMPS-containing polymer solution decreased with increase in temperature, in accordance with the Arrhenius equation. The oscillating period and the experimental temperature $\left(12-30{ }^{\circ} \mathrm{C}\right)$ have a linear relationship. From this linear relationship, the activation energy of the polymer solution was calculated to be $62.1 \mathrm{~kJ} / \mathrm{mol}$. The activation energy of the AMPS-containing polymer solution was almost the same as the BZ solution which does not include the self-oscillating polymer chain with $\mathrm{Ru}(\mathrm{bpy})_{3}$ [17]. This result demonstrated that covalently bonding $\mathrm{Ru}(\mathrm{bpy})_{3}$ to the AMPS-containing polymer chain does not inhibit the BZ reaction. Moreover, the activation energy of the polymer solution with $10 \mathrm{wt} \% \mathrm{Ru}(\mathrm{bpy})_{3}$ and $40 \mathrm{wt} \%$ AMPS was almost the same as the polymer chain used in this study [16]. This result suggested that the waveform of the transmittance self-oscillation does not affect the activation energy. 


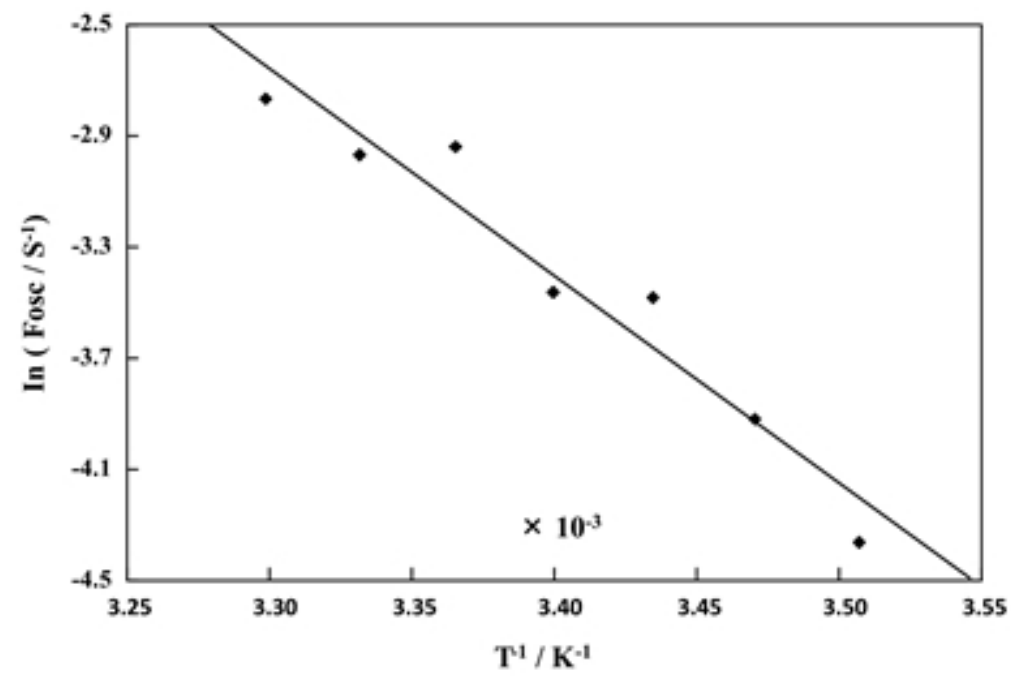

Fig. 4 Arrhenius dependence of the oscillating frequency $\left(\mathrm{F}_{\mathrm{osc}}\right)$ of the optical self-oscillation of poly(NIPAAm-co-Ru(bpy) ${ }_{3}$-co-AMPS) on temperature $\left(12-30{ }^{\circ} \mathrm{C}\right)$ with a fixed concentration of the BZ substrates $\left(\left[\mathrm{H}_{2} \mathrm{SO}_{4}\right]=0.3 \mathrm{M},\left[\mathrm{NaBrO}_{3}\right]=0.5 \mathrm{M},[\mathrm{MA}]=0.1 \mathrm{M}\right)$.

\section{Conclusion}

In this study, we clarified the waveform and activation energy of the self-oscillation utilizing the AMPS-containing polymer solution. The Ru(bpy $)_{3}$ and the AMPS contents affected the waveform of the transmittance self-oscillation, but did not affect the activation energy. The generating $\mathrm{CO}_{2}$ bubble inhibited measurement of the waveform of the self-oscillation. Therefore, in future, we plan to study the waveform of the self-oscillation of the polymer solution by using a BZ reaction that does not generate the $\mathrm{CO}_{2}$ bubble.

\section{Acknowledgments}

This work was supported by Grants-in-Aid (KAKENHI) for Young Scientists (B) (16K17493, 15K18014), and Scientific Research (B) (15H03827).

\section{References}

[1] A. N. Zaikin, A. M. Zhabotinsky, Concentration wave propagation in two-dimensional liquidphase self-oscillating system. Nature 225 (1970) 535-537.

[2] R. J. Field, E. Koros, R. M. Noyes, Oscillations in Chemical Systems II. Thorough analysis of temporal oscillations in the bromate-cerium-malonic acid system. J. Am. Chem. Soc. 94 (1972) 8649-8664.

[3] R. J. Field, R. M. Noyes, Oscillations in chemical systems. IV. Limit cycle behavior in a model of a real chemical reaction. J. Chem. Phys. 60 (1974) 1877-1884.

[4] E. J. Reusser, R. J. Field, The transition from phase waves to trigger waves in a model of the Zhabotinskii reaction. J. Am. Chem. Soc. 101 (1979) 1063-1071.

[5] J. J. Tyson, P. C. Fife, Target patterns in a realistic model of the Belousov-Zhabotinskii reaction. 73 (1980) 2224-2237.

[6] P. M. Wood, J. Ross, A quantitative study of chemical waves in the Belousov-Zhabotinsky reaction. J. Chem. Phys. 82 (1985) 1924-1936. 
[7] R. J. Field, M. Burger, Oscillations and Traveling Waves in Chemical Systems, John Wiley \& Sons, New York, 1985.

[8] L. Gyorgyi, T. Turanyi, R. J. Field, Mechanistic details of the oscillatory Belousov-Zhabotinsky reaction. J. Chem. Phys. 94 (1990) 7162-7170.

[9] T. Turanyi, L. Gyorgyi, R. J. Field, Analysis and simplification of the GTF model of the Belousov-Zhabotinsky reaction. J. Chem. Phys. 97 (1993) 1931-1941.

[10]T. Ishiwatari, M. Kawaguchi, M. Mitsuishi, Oscillatory reactions in polymer systems. J. Polym. Sci. Part A: Polym. Chem. 22 (1984) 2699-2704.

[11] R. Yoshida, T. Sakai, S. Ito, T. Yamaguchi, Self-oscillation of polymer chains with rhythmical soluble-insoluble changes. J. Am. Chem. Sci. 124 (2002) 8095-8098.

[12] Y. Hara, R. Yoshida, Control of Oscillating behavior for the self-oscillating polymer with pH-control site. Langmuir 21 (2005) 9773-9776.

[13] Y. Hara, R. Yoshida, Self-oscillation of polymer chains induced by the Belousov-Zhabotinsky reaction under acid-Free conditions. J. Phys. Chem. B 109 (2005) 9451-9454.

[14] Y. Hara, R. Yoshida, Self-oscillating polymer fueled by organic acid. J. Phys. Chem. B 112 (2008) 8427-8429.

[15] Y. Hara, R. Yoshida, Damping behavior of aggregation-disaggregation self-oscillation for a polymer chain. Marcomol. Rapid Commun. 30 (2009) 1656-1662.

[16] Y. Hara, Y. Takenaka, Autonomous oscillation of polymer chains induced by the Belousov-Zhabotinsky reaction. Sensors. 14 (2014) 1497-1510.

[17] L. Kuhnert, H. J. Krug, Kinetics of chemical waves in the acidic bromate-malonic acid-tris (bipyridine) ruthenium (2+) system in comparison with the ferroin system. J. Phys. Chem. 91 (1987) 730-733. 